\title{
Low physical fitness in childhood is associated with the development of asthma in young adulthood: the Odense schoolchild study
}

\author{
F. Rasmussen*, J. Lambrechtsen*, H.C. Siersted*, H.S. Hansen**, N.C.G. Hansen*
}

Low physical fitness in childhood is associated with the development of asthma in young adulthood: the Odense schoolchild study. F. Rasmussen, J. Lambrechtsen, H.C. Siersted, H.S. Hansen, N.C.G. Hansen. (C)ERS Journals Ltd 2000.

ABSTRACT: Intense physical activity in children may either improve fitness and protect against asthma, or may trigger symptoms. The aim of this study was to determine whether physical fitness in childhood has an impact on the development of asthma.

In this prospective, community-based study, 757 (84\%) asymptomatic children with an average age at inclusion of 9.7 yrs were followed for 10.5 yrs. In both surveys a maximal progressive exercise test on a bicycle ergometer was used to measure physical fitness (maximal workload) and to induce airway narrowing. A methacholine provocation test was performed in the subjects at follow-up.

During the 10-yr study period, $51(6.7 \%)$ of the previously asymptomatic children developed asthma. These subjects had a lower mean physical fitness in 1985 than their peers: (3.63 versus $\left.3.89 \mathrm{~W} \cdot \mathrm{kg}^{-1} ; \mathrm{p}=0.02\right)$ in boys and $\left(3.17\right.$ versus $\left.3.33 \mathrm{~W} \cdot \mathrm{kg}^{-1} ; \mathrm{p}=0.02\right)$ in girls. A weak correlation was found between physical fitness in childhood and airway responsiveness to methacholine at follow-up when adjusted for body mass index, age and sex $(r=0.11 ; p<0.01)$. In a multiple regression analysis, physical fitness was inversely related to the development of physician diagnosed asthma, odds ratio=0.93 $(0.87-0.99)$. Thus, the risk for the development of asthma during adolescence is reduced $7 \%$ by increasing the maximal workload $1 \mathrm{~W} \cdot \mathrm{kg}^{-1}$.

In conclusion, this study showed that physical fitness in childhood is weakly correlated with the development of asthma during adolescence and that high physical fitness seems to be associated with a reduced risk for the development of asthma.

Eur Respir J 2000; 16: 866-870.

Physical activity has beneficial effects in several diseases, e.g. cardiovascular disease, osteoporosis and cancer [1, 2]. Evidence for beneficial effects of physical activity in lung disease is more sparse. Exercise enhances growth of lungs in animals [3], but no firm evidence is present that exercise enhances growth of the lungs in humans. In one longitudinal study training of female swimmers had an impact on the development of the lungs [4]. In some lung diseases exercise training has been proven to be an essential component of pulmonary rehabilitation [5]. Exercise may induce larger respiratory manoeuvres that increase the range of motion of the chest cage and hence result in larger ventilatory capacities [6, 7]. In asthmatics physical exercise may trigger symptoms [8], causing physical activity to be reduced either by the subjects themselves or after recommendation by a health professional [9]. Several studies [9-11] have shown that asthmatic subjects often are less physically fit than their peers, but even severe asthmatics can achieve normal cardiopulmonary fitness after training [12]. Some studies $[13,14]$ have shown that improving physical fitness in asthmatic subjects is associated with reduced symptoms and medicine consumption, although this association has not been a consistent finding [15]. The physiological
*Dept of Respiratory Diseases, **Dept of Cardiology, Odense University Hospital, Denmark.

Correspondence: F. Rasmussen, Kløvervænget 2, Odense University Hospital, 5000 Odense C, Denmark. Fax: 45 65412728

Keywords: Asthma cohort study

childhood

longitudinal

physical fitness

Received: June 151999

Accepted after revision July 32000

The study was supported by the Danish Lung Association, The Danish Medical Research Council, Odense University, The Hørslev Foundation, K.A., Rohde and wife's foundation, Else and Mogens Wedell-Wedellsborg foundation. rationale for this effect may be that greater fitness includes a higher ventilatory threshold [16]. At an equal workload a subject would require a lower minute ventilation after training than before. Subjects with high physical activity in childhood may thus, influence their lungs favourably, so that they are better protected against asthma in later life. The aim of this study was therefore, to investigate whether physical fitness in childhood would have an impact on the subsequent risk for the development of asthma in adolescence.

\section{Materials and methods}

\section{Study subjects and design}

The Odense schoolchild study is a prospective multidisciplinary epidemiological study of a community-based cohort of 1,369 schoolchildren, first investigated during their third grade (8.5-11.0 yrs) in 1985. The details concerning selection and examination of the random baseline population have previously been published [17]. The present analysis is based on 896 nonasthmatics, asymptomatic children with a normal airway response after 
exercise in 1985. Of those, 757 (84\%) were reinvestigated at follow-up.

Parents gave informed consent prior to the participation of their children in 1985. Subjects gave informed consent before participating at follow-up. The study was approved by the local research ethics committee and the Danish Data Surveillance Authority.

\section{Pulmonary function tests}

Lung function was measured in the upright position using a McDermott bellows spirometer in 1985 and a pneumotachograph (Vitalograph (B) Compact; Vitalograph, Buckingham, UK) in 1996. The test was accepted if the two best values agreed within 5\%. The fitness test and the exercise challenge were performed in one sequence on both occasions [18]. The test was a maximal progressive exercise on an electrically braked ergometer cycle. The work load was increased every 3 min with an incremental increase based on the subject's weight and exercise data from the questionnaire. The subjects exercised for approximately five 3-min periods and heart rates were measured continuously by a Polar sport tester (PE-3000; Polar Electro OY, Kempele, Finland). Subjects were encouraged by the investigators to provide a maximal effort. The effort was accepted as maximal when the subject exceeded the individual $85 \%$ value of an expected maximal heart rate. The expected maximal heart rate was calculated as 220-age in years. Physical fitness was measured as the maximal workload $\left(\mathrm{W} \cdot \mathrm{kg}^{-1}\right)$. Forced expiratory volume in one second (FEV1) was measured 5 and 10 min after termination of exercise as the best of two acceptable recordings. Results were expressed as the lowest FEV1 obtained during the first $10 \mathrm{~min}$ after exercise as a percentage of the best pre-exercise value. An abnormal airway response after exercise was defined as a fall $>10 \%$ of pre-exercise FEV 1 measurement.

The methacholine provocation test was performed using an inhalation-triggered dosimeter (ME.FAR MB3 dosimeter; ME.FAR, Medicali, Brescia, Italy) at follow-up. A dosage protocol according to SIERSTED et al. [19] was used. Briefly, the first aerosol is dilutant followed by doubling concentrations of methacholine from $0.0625-2 \mathrm{mg}$ and cumulative dose range of $0.0625-4 \mathrm{mg}$. The response was measured by FEV1 and assessed after $60 \mathrm{~s}$ as the best of two technically satisfactory recordings. The highest value was used in the analysis. The results were expressed as the provocative dose of methacholine required to reduce FEV1 by $20 \%$ (PD20). Airway hyperresponsiveness to methacholine was determined as proposed by other authors [20] by considering the value delimiting the $5 \%$ with the highest fall in FEV1 in the reference subjects characterized by having no previous history of asthma or asthma-like symptoms [21]. This PD20 cut-off was 11.5 $\mu \mathrm{mol}$.

\section{Questionnaire}

In 1985, subjects with asthma were identified by the question: "Have you ever had asthma, i.e. periods of wheeze and/or cough?" and asthma-related symptoms by the questions, asked with reference to the previous 1-yr period: "Do you have wheeze and/or cough at rest?", "Do you have wheeze and/or cough when you are exercising?",
"Do you feel shortness of breath at night?", "Do you feel shortness of breath in the morning?", "Do you have wheeze and/or cough in foggy weather?" and "Do you have bronchitis, i.e. periodic cough during several days/ weeks?" At follow-up, asthma was identified by an affirmative answer to the question: "Is it your doctor's opinion that you have asthma?" Wheeze was identified by the question, asked with reference to the previous 1-yr period: "Do you have attacks of breathing trouble with wheezing or whistling?" [18]

The question: "Do you have hay fever?" was used to identify subjects with allergic rhinitis. Asthma in the family was noted, if at least one parent or one sibling had asthma in 1985. Subjects were labelled smokers, if their estimated lifetime tobacco consumption exceeded 1 pack-yr. The pack-year estimate was calculated by multiplying the tobacco consumption in $\mathrm{g} \cdot \mathrm{day}^{-1}$ with the duration of smoking in years divided by 20 .

\section{Statistical methods}

Differences in dichotomous and in continuously distributed variables were evaluated using the Chi-squared test and the t-test, respectively. The impact of physical fitness, sex, age, presence of allergic rhinitis, tobacco consumption exceeding 1 pack-yr, body mass index (BMI), FEV1 in per cent of predicted, and a family history of asthma was assessed by logistic regression using forced entry. The strength of association was expressed as an odds ratio $(\mathrm{OR})$. Three different outcome variables were tested in the regression: physician diagnosed asthma, presence of hyperresponsiveness to methacholine and hyperresponsiveness to methacholine in combination with symptoms of wheeze within the previous year. As no sex-specific differences were seen in regard to the effect of physical fitness, all further analyses were performed with males and females in one model. Two-tailed tests were used with a 5\% significance level. Statistical analysis was performed with Statistical Package for Social Sciences (SPSSPC+7.5.1) (SPSS Inc., Chicago, IL, USA).

\section{Results}

Four hundred and seventy-three subjects (35\%) with asthma, asthma-related symptoms or a fall in FEV $1>10 \%$ after exercise in childhood were dismissed from the analysis. Of the remaining 896 subjects at baseline, 757 $(84 \%)$ were reinvestigated at follow-up. No statistical significant differences were found between participants and nonparticipants at follow-up in regard to sex, age, birthweight or to data measured in 1985: prevalence of allergic rhinitis, physical fitness, height, weight, BMI, FEV1 \% pred, and forced vital capacity (FVC) \% pred. At follow-up, the methacholine provocation test, physical fitness and exercise challenge was accepted in $588(78 \%), 603(80 \%)$ and in 599 subjects $(79 \%)$, respectively. Demographic data were compared between those subjects who participated in the tests and those who did not perform the tests and no significant differences were found.

Characteristics including anthropometric and spirometric data of the study subjects are summarized at baseline in table 1 and at follow-up in table 2 . 
Table 1. - Baseline characteristics of the participants.

\begin{tabular}{lcccc}
\hline & \multicolumn{2}{c}{ Male } & \multicolumn{2}{c}{ Female } \\
\cline { 2 - 5 } & Asthma & $\begin{array}{c}\text { No } \\
\text { asthma }\end{array}$ & Asthma & $\begin{array}{c}\text { No } \\
\text { asthma }\end{array}$ \\
\hline $\begin{array}{l}\text { Subjects n } \\
\text { Physical } \\
\text { fitness }\end{array}$ & 18 & 370 & 33 & 336 \\
$\begin{array}{l}\text { W.kg } \\
\text { Age yrs }\end{array}$ & $9.63 \pm 0.54 *$ & $3.89 \pm 0.59$ & $3.17 \pm 0.45^{*}$ & $3.33 \pm 0.51$ \\
FEV1 \% pred & $100 \pm 11$ & $101 \pm 10$ & $101 \pm 11$ & $100 \pm 10$ \\
$\begin{array}{l}\text { FVC \% pred } \\
\text { BMI kg.m }\end{array}$ & $103 \pm 9$ & $101 \pm 11$ & $101 \pm 11$ & $100 \pm 10$ \\
\% fall in & $2.3 \pm 3.5$ & $0.7 \pm 4.3$ & $16.7 \pm 1.8$ & $16.8 \pm 2.0$ \\
$\begin{array}{l}\text { FEV1 } \\
\text { after exercise }\end{array}$ & & & & $0.9 \pm 3.8$ \\
$\begin{array}{c}\text { Asthma in the } \\
\text { family \% }\end{array}$ & $17 \%$ & $4 \%$ & $21 \%$ & $10 \%$ \\
$\begin{array}{c}\text { Allergic } \\
\text { rhinitis \% }\end{array}$ & $28 \%{ }^{*}$ & $2 \%$ & $19 \%{ }^{\#}$ & $3 \%$ \\
\hline
\end{tabular}

The subjects are grouped according to sex and asthma status at follow-up. Values presented as mean \pm SD unless otherwise stated. FEV1: forced expiratory volume in one second; FVC: forced vital capacity; BMI: body mass index; ${ }^{*}: \mathrm{p}<0.05$; $^{\sharp}: \mathrm{p}<0.01$. The p-values refer to sex-specific comparisons between asthmatics and nonasthmatics.

\section{Physical fitness and the development of asthma}

Among the 757 previously asymptomatic children 51 $(6.7 \%)$ had physician diagnosed asthma at follow-up. Those who developed physician diagnosed asthma had lower mean physical fitness than their peers: (3.63 versus $\left.3.89 \mathrm{~W} \cdot \mathrm{kg}^{-1} ; \mathrm{p}=0.02\right)$ and $\left(3.17\right.$ versus $3.33 \mathrm{~W} \cdot \mathrm{kg}^{-1}$; $\mathrm{p}=0.02$ ) in male and female children. Physical fitness at baseline was stratified in quintiles and the development of asthma was compared between the groups (fig. 1). A

Table 2. - Demographic characteristics of the subjects at follow-up.

\begin{tabular}{|c|c|c|c|c|}
\hline & \multicolumn{2}{|c|}{ Male } & \multicolumn{2}{|c|}{ Female } \\
\hline & Asthma & $\begin{array}{l}\text { No } \\
\text { asthma }\end{array}$ & Asthma & $\begin{array}{l}\text { No } \\
\text { asthma }\end{array}$ \\
\hline Subjects n & 18 & 370 & 33 & 336 \\
\hline $\begin{array}{l}\text { Physical fitness } \\
W \cdot \mathrm{kg}^{-1}\end{array}$ & $3.48 \pm 0.80$ & $3.64 \pm 0.64$ & $2.65 \pm 0.61$ & $2.75 \pm 0.54$ \\
\hline Age yrs & $20.3 \pm 0.6$ & $20.2 \pm 0.6$ & $20.1 \pm 0.7$ & $20.1 \pm 0.6$ \\
\hline FEV1 \% pred & $95 \pm 12^{*}$ & $99 \pm 11$ & $100 \pm 10$ & $101 \pm 11$ \\
\hline FVC \% pred & $100 \pm 9$ & $99 \pm 10$ & $98 \pm 12$ & $100 \pm 11$ \\
\hline $\mathrm{BMI} \mathrm{kg} \cdot \mathrm{m}^{-2}$ & $22.7 \pm 2.2$ & $23.3 \pm 3.6$ & $23.1 \pm 5.2$ & $22.6 \pm 3.1$ \\
\hline $\begin{array}{l}\% \text { fall in FEV } 1 \\
\text { after exercise }\end{array}$ & $5.8 \pm 3.8^{*}$ & $3.9 \pm 3.6$ & $7.3 \pm 4.5^{\#}$ & $4.5 \pm 3.6$ \\
\hline PD20 $\mu \mathrm{mol}$ & $\begin{array}{c}9.1^{\#} \\
(0.6-20.5)\end{array}$ & $\begin{array}{c}20.5 \\
(0.9-20.5)\end{array}$ & $\begin{array}{c}16.9 \\
(0.5-20.5)^{*}\end{array}$ & $\begin{array}{c}20.5 \\
(1.5-20.5)\end{array}$ \\
\hline $\begin{array}{l}\text { Asthma-like } \\
\text { symptoms \% }\end{array}$ & $78^{\#}$ & 17 & $79^{\#}$ & 26 \\
\hline
\end{tabular}

The participants are grouped according to sex and asthma status at follow-up. Data preserved as mean $\pm \mathrm{SD}$ or median (range). FEV1: forced expiratory volume in one second; FVC: forced vital capacity; BMI: body mass index; PD20: provocative dose of methacholine to give use to a $20 \%$ fall in $\mathrm{FEV} 1 ;{ }^{*}$ : $\mathrm{p}<0.05$; $^{*}$ : $\mathrm{p}<0.01$. $\mathrm{p}$-values refer to sex-specific comparisons between asthmatics and nonasthmatics.

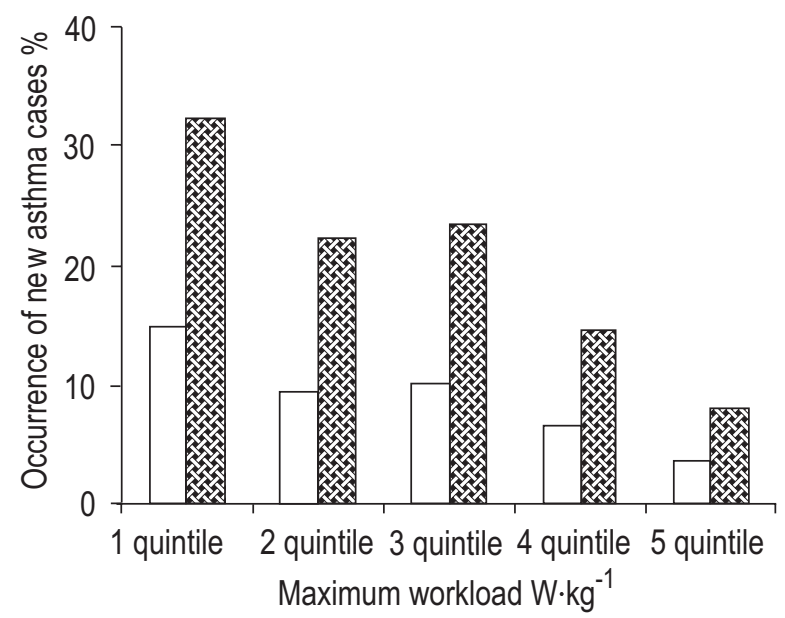

Fig. 1. - The occurrence of new asthma cases according to the quintiles of physical fitness in 1985. The proportion of new asthma cases in the fitness intervals are shown as a percentage of all new asthma cases (젔) and according to the percentage of subjects in the particular fitness interval $(\square)$

falling rate of new asthma cases was seen through the quintiles and with no obvious cut-off point. Therefore, physical fitness was included in all regressions as a continuous variable. A weak correlation was found between physical fitness in 1985 and airway reactivity in 1996 when adjusted for sex, age and BMI (table 3). The influence of physical fitness on the development of asthma was assessed by multiple logistic regression. The three outcome variables tested are shown in table 4 . The multiple regression analysis showed that physical fitness in 1985 was inversely associated with the presence of physician diagnosed asthma at follow-up $\mathrm{OR}=0.93$ (0.87-0.99). Presence of allergic rhinitis and asthma in the family were the only other variables independently associated with the development of physician diagnosed asthma. Physical fitness was not statistically significantly associated with "hyperresponsiveness to methacholine" or "hyperresponsiveness to methacholine with symptoms of wheeze" when adjusted for all the other risk factors in the model.

\section{Discussion}

To the authors' knowledge this is the first study to investigate the association between physical fitness in childhood and the development of asthma in adolescence.

Table 3. - Correlation coefficients between maximal workload, airway responsiveness to methacholine and maximal fall in forced expiratory volume in one second (FEV1) after exercise.

\begin{tabular}{lcc}
\hline \multicolumn{3}{c}{ Correlation coefficients } \\
\hline & $\begin{array}{c}\text { Max fall in FEV1 } \\
\text { after exercise in 1996 }\end{array}$ & $\begin{array}{c}\text { PD20 } \\
\text { in 1996 }\end{array}$ \\
\hline Physical fitness in 1985 & $-0.11^{*}$ & $0.11^{\#}$ \\
Physical fitness in 1996 & $-0.09^{*}$ & $0.10^{\#}$ \\
\hline
\end{tabular}

The associations are adjusted for sex, age and body mass index. All correlations (*: Pearson; \#: Spearman's) are significant $(p<0.01)$. PD20: provocative dose of methacholine that gives rise to a $20 \%$ fall in FEV1. 
Table 4. - Adjusted associations of risk factors and their 95\% confidence interval with physician diagnosed asthma, hyperresponsiveness to methacholine and hyperresponsiveness to methacholine with symptoms of wheeze as the three outcome variables.

\begin{tabular}{|c|c|c|c|}
\hline & Physician diagnosed asthma & $\begin{array}{l}\text { Hyperresponsiveness to } \\
\text { methacholine and symptoms } \\
\text { of wheeze }\end{array}$ & $\begin{array}{c}\text { Hyperresponsiveness to } \\
\text { methacholine } \\
\text { PD } 20 \leqslant 11.5 \mu \mathrm{mol}\end{array}$ \\
\hline Physical fitness in $1985 \mathrm{~W} \cdot \mathrm{kg}^{-1}$ & $0.93(0.87-0.99)$ & $1.00(0.93-1.07)$ & $1.03(0.97-1.10)$ \\
\hline BMI in $1985 \mathrm{~kg} \cdot \mathrm{m}^{-2}$ & $0.98(0.81-1.17)$ & $1.11(0.89-1.39)$ & $1.17(0.96-1.43)$ \\
\hline Allergic rhinitis & $5.0(2.0-12.3)$ & $4.7(2.0-11.3)$ & $1.4(0.4-5.3)$ \\
\hline Asthma in the family & $1.9(0.8-4.5)$ & $2.9(1.3-6.5)$ & $1.5(0.6-3.5)$ \\
\hline
\end{tabular}

Adjusted for all factors including sex, age, forced expiratory volume in one second (FEV1), \% pred and tobacco smoking. PD20: provocative dose of methacholine giving rise to a $20 \%$ fall in FEV1; BMI: body mass index.

The findings suggest that the risk for the development of asthma during adolescence is reduced $7 \%$ by increasing the maximal workload with $1 \mathrm{~W} \cdot \mathrm{kg}^{-1}$.

The association between physical fitness and the development of asthma was not due to unrecognized asthmatics at baseline since all subjects included were nonasthmatic, asymptomatic subjects and with a normal airway response after exercise. Physician-diagnosed asthma, the presence of hyperresponsiveness to methacholine alone or in the combination with symptoms of wheeze, were associated with low physical fitness when adjusted for BMI, age and sex. When stronger risk factors such as asthma in the family and allergic rhinitis were added, physical fitness was only associated with the development of physician diagnosed asthma. Thus, the effect of physical fitness was solely shown on the development asthma as diagnosed by a physician and not on the development of hyperresponsiveness to methacholine alone or in combination with symptoms of wheeze.

This finding suggests that the effect of physical fitness as measured the maximal workload is small and that the choice of the asthma definition may be of great importance. The phenotype of asthma may change from childhood to adolescence [22] and physical fitness may only have an effect in specific age groups and in certain groups of asthmatics. GILLIAN et al. [23] hypothesized that prepubescent children are unable to elicit physiological changes in response to training. КАTCH [24] proposed that the critical time period of training exists around puberty and an effect of training would be seen over this age. Thus, the association does not necessarily exist in other age groups or when other definitions of asthma are used. Improved physical fitness in asthmatic subjects has, in some studies, contributed to a reduction in the occurrence of respiratory symptoms and medicine consumption [13, $14,25]$ but not in all studies [15]. The ability of physical training to reduce the fall in FEV1 after exercise is also conflicting $[15,26]$. This may be due to the weak correlation between physical fitness and airway reactivity. In a smaller study, GARFINKEL et al. [27] were unable to show a significant correlation between physical fitness and the provocative concentration giving rise to a $20 \%$ fall in FEV1.

It is suggested that physical fitness has its effect on asthma independently of the basic inflammatory processes that are thought to operate in the disease. Several explanations are possible. The sensation of respiratory symptoms, and their report, can be influenced by the persons fitness [25]. High fitness could raise the person's "threshold" to respiratory symptoms and raise the level at which respiratory discomfort develops. MAHLER et al. [28] proposed that these effects are induced by alterations in brain ventilatory chemosensitivity. LONDEREE et al. [16] suggested that greater fitness includes a higher ventilatory threshold and a relatively lower ventilation means a smaller ventilatory stimulus to asthma. Exercise could induce larger respiratory manoeuvres that increases the range of motion of the chest cage and hence result in larger ventilatory capacities $[6,7]$. Thus, subjects with high activity in childhood may influence their lungs favourably so that they are better protected against asthma in later life. Some of the subjects who later developed asthma may be those who adopt low activity to avoid unpleasant respiratory symptoms. This could start a vicious circle of diminished physical activity which further aggravates the disease and provokes symptoms at an even lower level of activity [8].

The actual levels of physical fitness in the presented sample are in accordance with previous studies [29]. ARMSTRONG [30] pointed out that physical fitness measured as a maximal workload did not necessarily correlate with the subjects habitual physical activity, but it is an objective measure of the subjects physical potential and a useful research tool. A single measure of aerobic capacity as a marker of physical fitness over a decade may appear to be inaccurate, but it has previously been shown to be reasonable $[1,29]$. The present study confirms previous findings that asthma in the family and presence of allergic rhinitis were risk factors associated with the development of asthma and airway reactivity $[21,31]$.

In conclusion, this study showed a weak relationship between physical fitness in childhood and the development of asthma during adolescence. Subjects with low physical fitness were at a higher risk for the subsequent development of asthma compared to subjects with high physical fitness.

Acknowledgements. The authors thank N. Hyldebrandt who inspired H.S. Hansen to initiate this cohort. Further they wish to thank the subjects and their parents for their participation.

\section{References}

1. Blair SN, Franks AL, Shelton DM, Livengood JR, Hull FL, Breedlove B. Physical Activity and Health: a Report of the Surgeon General. USA, 1996. 
2. Orenstein DM. Exercise and the young. Compr Ther 1985; 11: 38-47.

3. Thurlbeck L, Chernick V, Mellins RB, eds. Basic Mechanisms of Paediatric Respiratory Disease: Cellular and Integrative. Philadelphia, Decker, 1991; pp. 23-36.

4. Zeltner TB, Caduff JH, Gehr P, Pfenninger J, Burri PH. The postnatal development and growth of the human lung. I. Morphometry. Respir Physiol 1987; 67: 247-267.

5. Gosselink R, Troosters T, Decramer M. Exercise training in COPD patients: the basic questions. Eur Respir J 1997; 10: 2884-2891.

6. Brody JS, Lahiri S, Simpser M, Motoyama EK, Velaszuez T. Lung elasticity and airway dynamics in Peruvian natives to high altitude. J Appl Physiol 1977; 42: 245251.

7. Armour J, Donnelly PM, Bye PT. The large lungs of elite swimmers: an increased alveolar number? Eur Respir $J$ 1993; 6: 237-247.

8. Schwartzstein RM. Asthma: to run or not to run? Am Rev Respir Dis 1992; 145: 739-740.

9. Orenstein DM, Reed ME, Grogan-FT J, Crawford LV. Exercise conditioning in children with asthma. $J$ Pediatr 1985; 106: 556-560.

10. Clark CJ, Cochrane LM. Assessment of work performance in asthma for determination of cardiorespiratory fitness and training capacity. Thorax 1988; 43: 745-749.

11. Varray A, Mercier J, Savy PA, Prefaut C. Cardiac role in exercise limitation in asthmatic subjects with special reference to disease severity. Eur Respir J 1993; 6: 10111017.

12. Ludwick SK, Jones JW, Jones TK, Fukuhara JT, Strunk RC. Normalization of cardiopulmonary endurance in severely asthmatic children after bicycle ergometry therapy. J Pediatr 1986; 109: 446-451.

13. Szentagothai K, Gyene I, Szocska M, Osvath P. Physical exercise program for children with bronchial asthma. Pediatr Pulmonol 1987; 3: 166-172.

14. Fitch KD, Morton AR, Blanksby BA. Effects of swimming training on children with asthma. Arch Dis Child 1976; 51: 190-194.

15. Nickerson BG, Bautista DB, Namey MA, Richards W, Keens TG. Distance running improves fitness in asthmatic children without pulmonary complications or changes in exercise-induced bronchospasm. Pediatrics 1983; 71: 147-152.

16. Londeree BR. Effect of training on lactate/ventilatory thresholds: a meta-analysis. Med Sci Sports Exerc 1997; 29: 837-843.

17. Hansen HS, Hyldebrandt N, Nielsen JR, Froberg K. Blood pressure distribution in a school-age population aged 8-10 years: the Odense Schoolchild Study. J Hypertens 1990; 8: 641-646.

18. Rasmussen F, Lambrecthsen L, Siersted HC, Hansen HS, Hansen NC. Asymptomatic bronchial hyperresponsiveness to exercise in childhood and the development of asthma related symptoms in young adulthood. Thorax 1999; 54: 587-589.

19. Siersted HC, Mostgaard G, Hyldebrandt N, Hansen HS, Boldsen $\mathrm{J}$, Oxhoj $\mathrm{H}$. Interrelationships between diagnosed asthma, asthma-like symptoms, and abnormal airway behaviour in adolescence: the Odense Schoolchild Study. Thorax 1996; 51: 503-509.

20. Godfrey S, Springer C, Noviski N, Maayan C, Avital A. Exercise but not methacholine differentiates asthma from chronic lung disease in children. Thorax 1991; 46: 488492.

21. Rasmussen F, Lambrecthsen L, Siersted HC, Hansen HS, Hansen NC. Increased eosinophil cation protein levels in sensitized non-asthmatics is linked to subsequent hyperresponsiveness to methacholine. The Odense schoolchild study. Int Arch Allergy Immunol 2000; 121: 129-136.

22. Clough JB. Phenotype stability in asthma and atopy in childhood. Clin Exp Allergy 1998; 28 (Suppl 1): 22-25.

23. Gilliam TB, Freedson PS. Effects of a 12-week school physical fitness program on peak $\mathrm{VO}_{2}$, body composition and blood lipids in 7 to 9 year old children. Int J Sports Med 1980; 1: pp. 73-78.

24. Katch VL. Physical conditioning of children. J Adolesc Health Care 1983; 3: 241-246.

25. Clark CJ. The role of physical training in asthma. Chest 1992; 101 (Suppl 5): 293S-298S.

26. Henriksen JM, Nielsen TT. Effect of physical training on exercise-induced bronchoconstriction. Acta Paediatr Scand 1983; 72: 31-36.

27. Garfinkel SK, Kesten S, Chapman KR, Rebuck AS. Physiologic and nonphysiologic determinants of aerobic fitness in mild to moderate asthma [published erratum appears in Am Rev Respir Dis 1992 Jul; 146: 269]. Am Rev Respir Dis 1992; 145: 741-745.

28. Mahler DA, Cunningham LN, Skrinar GS, Kraemer WJ, Colice GL. Beta-endorphin activity and hypercapnic ventilatory responsiveness after marathon running. J Appl Physiol 1989; 66: 2431-2436.

29. Armstrong N, Welsman J. Young People and Physical Activity. Oxford, Oxford University Press, 1997.

30. Armstrong N. Young people's physical activity patterns as assessed by heart rate monitoring. J Sports Sci 1998; 16 : S9-S16.

31. Sears MR. Epidemiology of childhood asthma. Lancet 1997; 350: 1015-1020. 